\title{
Management of Severe Radiation Proctitis with Radiofrequency Ablation
}

\author{
Joana Castela Susana Mão de Ferro Sara Ferreira António Dias Pereira \\ Department of Gastroenterology, Instituto Português de Oncologia de Lisboa Francisco Gentil, Lisbon, Portugal
}

\section{Keywords}

Radiation proctitis · Gastrointestinal bleeding .

Radiofrequency ablation

\section{Abordagem de proctite rádica grave com ablação por radiofrequência}

\section{Palavras Chave}

Proctite rádica $\cdot$ Hemorragia digestiva $\cdot$ Ablação por radiofrequência

We report the case of a 74-year-old female with a uterine carcinosarcoma with lung metastasis, who underwent pelvic radiotherapy (RT) followed by chemotherapy. Four months after RT, she presented with multiple episodes of rectal bleeding and anemia, requiring regular transfusions. Upper endoscopy was unremarkable and colonoscopy showed erythema, telangiectasias with coalescing patches, friability, and sparse ulcers, extending from the dentate line to the distal sigmoid colon, consistent with severe radiation proctitis (RP). The patient underwent two sessions of argon plasma coagulation (APC) therapy with clinical inefficacy, and required a total of 27

\section{KARGER}

E-Mail karger@karger.com www.karger.com/pig
(C) 2018 Sociedade Portuguesa de Gastrenterologia

Published by S. Karger AG, Basel

Karger

Open access

This article is licensed under the Creative Commons AttributionNonCommercial-NoDerivatives 4.0 International License (CC BYNC-ND) (http://www.karger.com/Services/OpenAccessLicense). Usage and distribution for commercial purposes as well as any distribution of modified material requires written permission. red blood cell transfusions and intravenous iron. Chemotherapy was suspended due to clinical deterioration. Six months after RT, she was admitted with profuse rectal bleeding, hypotension, and severe anemia (hemoglobin of $4.2 \mathrm{~g} / \mathrm{dL}$ ), requiring hemodynamic resuscitation. Colonoscopy revealed several telangiectasias, with multiple clots and oozing bleeding (Fig. 1). Considering the severity and extension of the disease and the limited efficacy of APC therapy, we performed radiofrequency ablation (RFA). Standard bowel preparation with $4 \mathrm{~L}$ of polyethylene glycol was done. After cleaning and aspiration of the blood content, the focal Halo90 catheter (Halo ${ }^{\circledR}$ system, Covidien GI Solutions, Sunnyvale, CA, USA) was placed at the 6 o'clock position onto the distal end of the gastroscope (GIF-190, Olympus). The catheter was pressed against the rectal mucosa and 2 energy pulses were applied per site (Fig. 2) (energy of $12 \mathrm{~J} / \mathrm{cm}^{2}$, power density of $40 \mathrm{~W} / \mathrm{cm}^{2}$ ). The ablated tissue was not removed after the first energy pulse to promote the hemostatic effect. The treatment was repeated from the proximal border of the radiation changes to the lower rectum. The distal rectum was ablated in retroflexion. Full circumference ablation was avoided to minimize the risk of stenosis [1]. Hemostasis was achieved at the end of the procedure and 

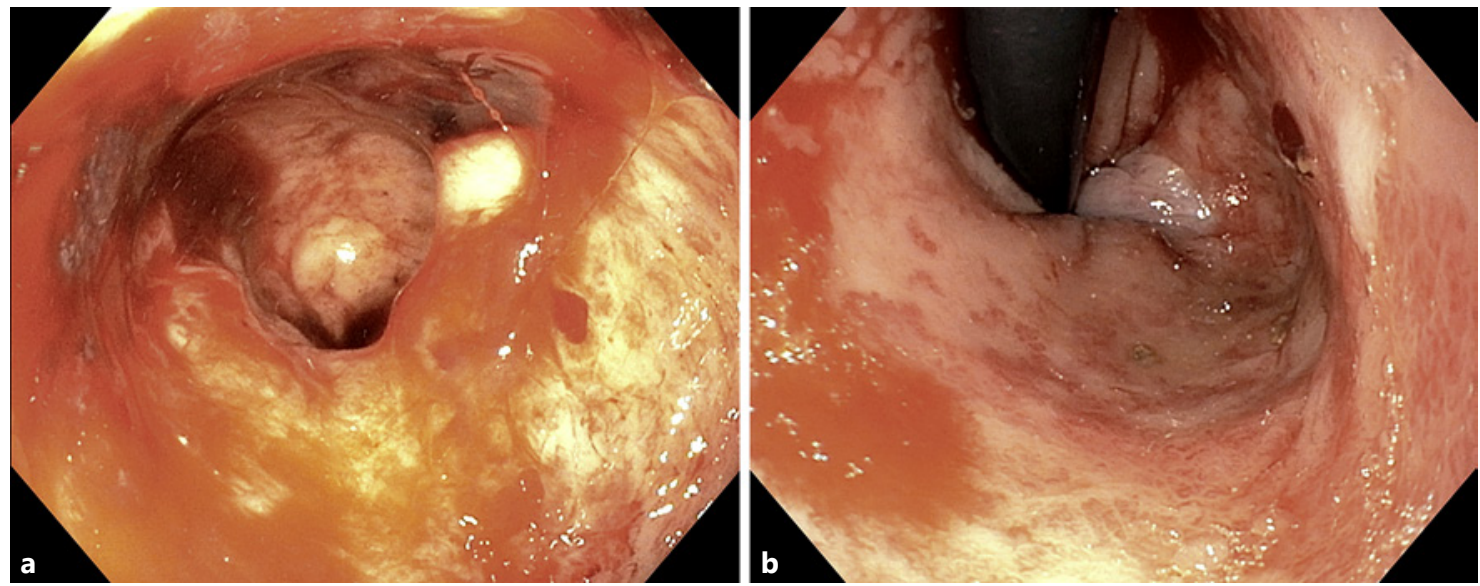

Fig. 1. Endoscopic axial (a) and retroflexion view (b) of the rectum revealing edematous rectal mucosa with multiple telangiectasias, friability, and oozing bleeding before treatment.
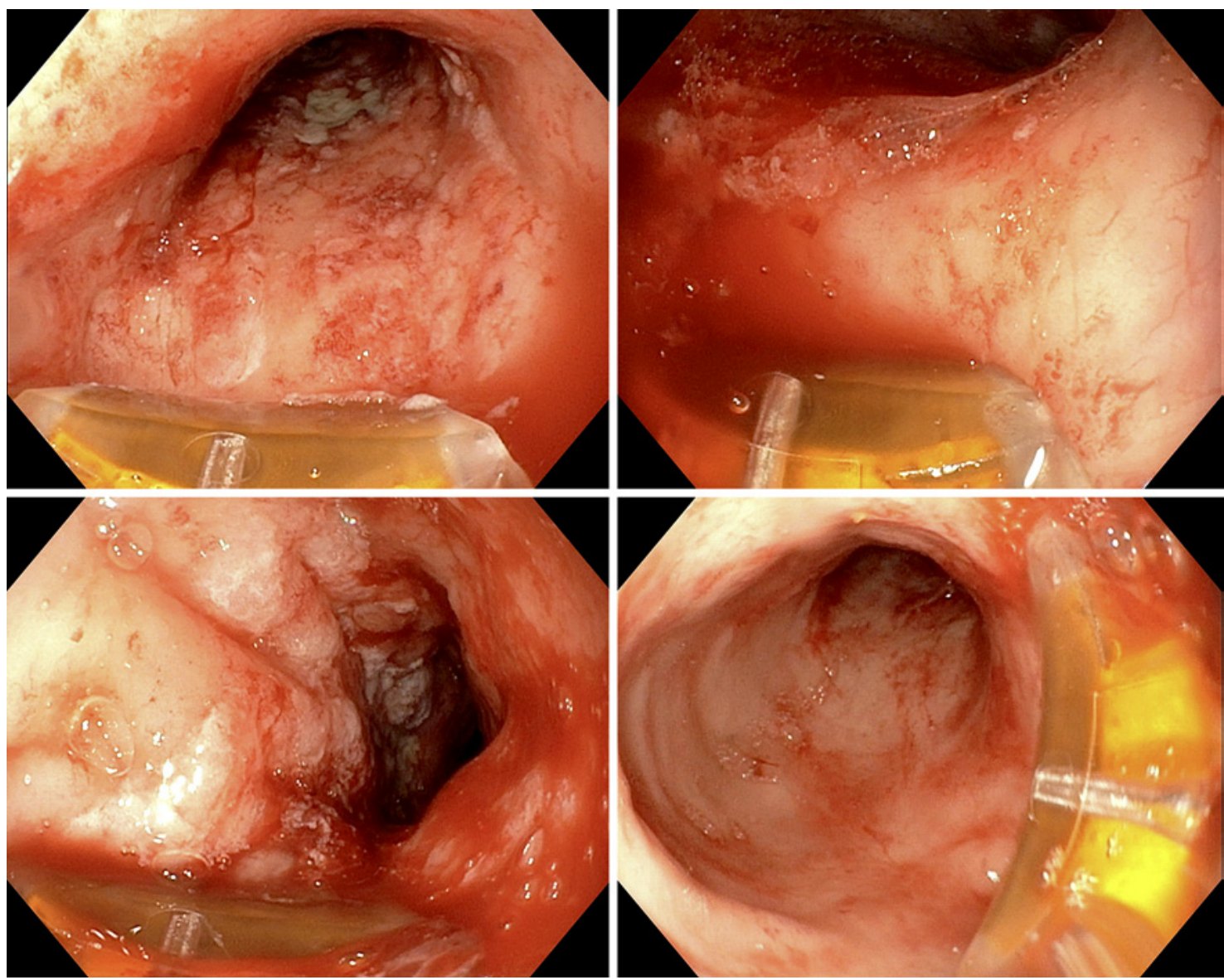

Fig. 2. Endoscopic view of the rectum with Halo90 probe (Covidien GI Solutions, Sunnyvale, CA, USA) placed at the 6 o'clock position. The catheter is applied against the rectal pathological tissue and energy pulse is delivered (energy setting of $12 \mathrm{~J} / \mathrm{cm}^{2}$ and a power density of $40 \mathrm{~W} / \mathrm{cm}^{2}$ ), with 2 applications of the RFA per site. The ablated tissue is not scraped off and the scope is moved to the adjacent mucosa, successively (43 pulses total). 

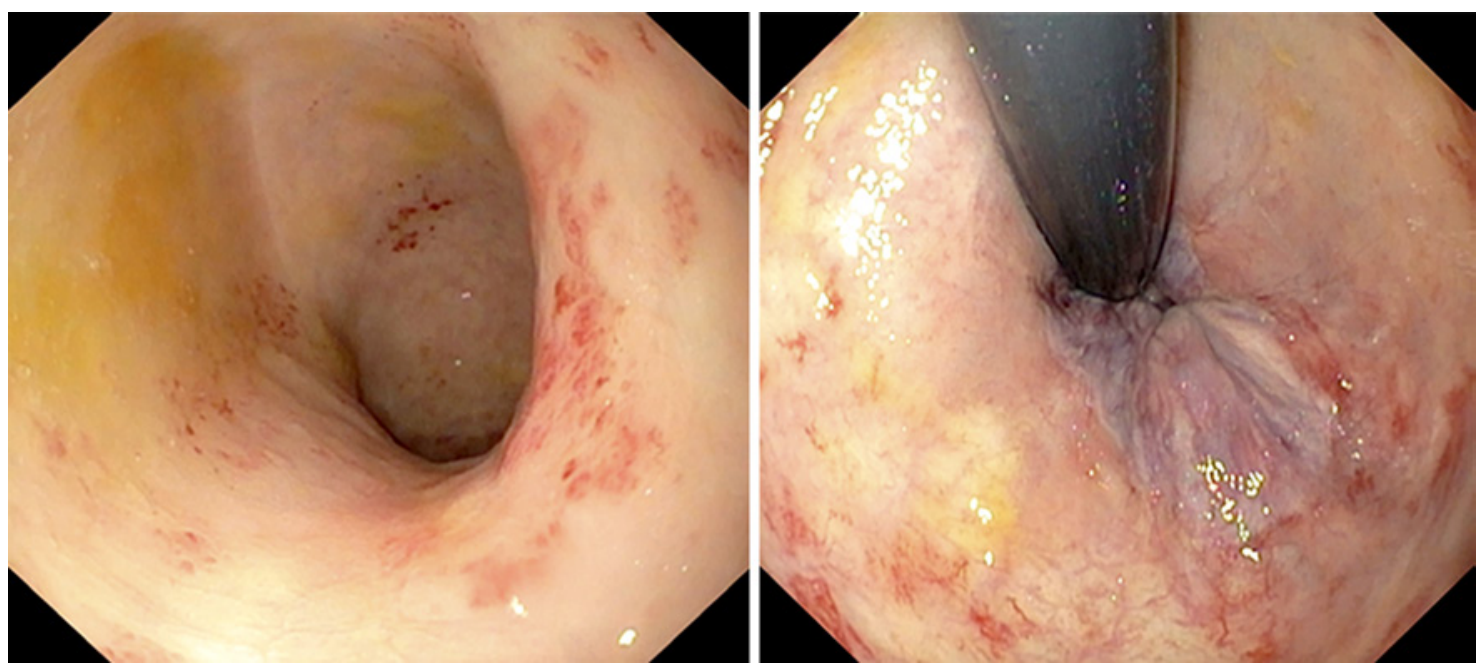

Fig. 3. Follow-up sigmoidoscopy, 3 months after RFA therapy, showing a healed rectal mucosa, with sparse telangiectasias, with no friability or bleeding.

no complications were recorded. Following the procedure, no further rectal bleeding occurred; the patient was discharged and resumed chemotherapy 1 month later. Endoscopic re-evaluation, 3 months after RFA, revealed sparse telangiectasias with no friability or bleeding (Fig. 3). At 6 months of follow-up, the patient maintained no rectal bleeding, stable hemoglobin (mean: $10 \mathrm{~g} / \mathrm{dL}$ ) and no further need for blood transfusions.

Chronic RP is a complication of RT for pelvic malignancies, reported in up to $20 \%$ of the patients $[1,2]$. APC is considered the preferred therapy, with an overall success rate as high as $80 \%[1,3]$. However, it has been associated with serious complications (e.g., perforation, fistulas, and strictures), and the efficacy is limited in patients with active bleeding, extensive disease and distally located lesions (anorectal junction) [2, 4]. RFA covers a broader area, has a superficial depth of ablation $(0.5-1 \mathrm{~mm})$, reducing the potential risk for fibrosis and stricture formation $[2,3]$, and has emerged as a promising alternative treatment [1]. According to Rustagi et al. [1], who published the largest series of patients managed by RFA ( $n=$ 39 ), this technique showed $96 \%$ improvement of the endoscopic severity score, $100 \%$ efficacy in stopping bleeding, and $92 \%$ of blood transfusion discontinuation, with no major complications [1]. We believe RFA should be contemplated as a treatment option for RP, especially for extensive and severe cases.

\section{Statement of Ethics}

This study did not require informed consent nor review/approval by the appropriate ethics committee.

\section{Disclosure Statement}

The authors declare no conflicts of interest.

\section{References}

1 Rustagi T, Corbett FS, Mashimo H: Treatment of chronic radiation proctopathy with radiofrequency ablation (with video). Gastrointest Endosc 2015;81:428-436.

2 Dray X, Battaglia G, Wengrower D, Gonzalez $\mathrm{P}$, Carlino A, Camus M, Adar T, Pérez-Roldán F, Marteau P, Repici A: Radiofrequency ablation for the treatment of radiation proctitis. Endoscopy 2014;46:970-976.
3 Eddi R, Depasquale JR: Radiofrequency ablation for the treatment of radiation proctitis: a case report and review of literature. Therap Adv Gastroenterol 2013;6:69-76.

4 Becq A, Camus M, Rahmi G, de Parades V, Marteau P, Dray X: Emerging indications of endoscopic radiofrequency ablation. United European Gastroenterol J 2015;3:313-324. 